\title{
Multiple causes of asphyxia in infants at high risk for sudden infant death
}

\author{
H E JEFFERY, P RAHILLY, AND D J C READ \\ Department of Physiology, University of Sydney, and Royal Alexandra Hospital for Children, Australia
}

SUMMARY A wide range of clinical findings was present in 58 near-miss sudden infant death syndrome (SIDS) infants and 6 surviving twins of SIDS siblings. Specific investigations included: studies of gastro-oesophageal reflux and aspiration (24-hour oesophageal $\mathrm{pH}$ recordings, barium swallow, radionuclide 'milk-scan'); polygraphic studies of breathing, reflux, and sleep state; studies of upper airways disease (lateral airways radiography and endoscopy); detection of seizure activity by electroencephalography; evaluation of thiamine status by erythrocyte transketolase activity of venous blood. Thiamine deficiency was found in 12 of 43 tested infants; 5 of the deficient infants had a familial history of SIDS. Many potential mechanisms for asphyxia were found: idiopathic central apnoea (7 infants), tracheal obstruction from minimal tracheomalacia or aberrant innominate artery (4 infants), temporal lobe or generalised seizures (6 infants), gastro-oesophageal reflux (55 infants) with intrapulmonary aspiration (11 infants). The high incidence, severity, and timing of reflux were new findings. Reflux occurred in active and indeterminate sleep, but not in quiet sleep. The depression of respiratory reflexes by active sleep stresses the vulnerability to asphyxia. Two factors suggest that near-miss episodes are related to SIDS: the similar age distribution but earlier occurrence of near-miss episodes compared with age at death of SIDS infants, and the subsequent sudden death of 2 infants whose necropsies were consistent with SIDS.

The sudden infant death syndrome (SIDS) is still the most common cause of infant mortality after 1 month of age in western countries.

Infants considered at higher risk of SIDS than the general population are referred to as 'near-miss' SIDS infants. Such infants present with an apparent asphyxial episode during sleep and usually require some form of stimulation or resuscitation before normal breathing resumes. Some of these infants subsequently die suddenly and necropsy findings are consistent with SIDS. ${ }^{1-4}$

An infant at high risk of SIDS is the surviving twin or triplet of a SIDS sibling. ${ }^{5}$

Infants at high risk of SIDS are becoming more widely recognised and constitute an increasing diagnostic and therapeutic dilemma. Initially, abnormalities in breathing-such as prolonged apnoea-were recognised in some. ${ }^{12}$ More recently there have been reports of excessive periodic breathing ${ }^{67}$ and specific defects both in $\mathrm{CO}_{2}$ chemoreceptor and hypoxic chemoreceptor reflexes. $^{28}$

Apart from these specific abnormalities in breathing, this paper describes a broad clinical overview of the findings in 64 high risk SIDS infants who were screened for a variety of possible causes, in addition to respiratory ones.

\section{Methods}

During the 2-year period April 1979-81, 64 infants were studied. They comprised 58 suspected near-miss infants and 6 surviving twins or triplets of a SIDS sibling. A near-miss infant was defined as one who was found during presumed sleep to be apnoeic, cyanotic or pale, often limp, and required either resuscitation or vigorous stimulation for revival. Such infants were admitted to or referred within the Royal Alexandra Hospital for Children, Sydney, to a newly formed clinic which (1) screened infants thought to have had a near-miss episode; (2) assessed siblings of SIDS infants, especially if the infant was a surviving twin or triplet; and (3) provided an immediate pathological report to SIDS parents and provided information and counselling for such parents.

After admission, a detailed clinical assessment was made from (1) the clinical history, documented on a standard questionnaire form: this included details of the near-miss episode and the health of the infant preceding the event; the pregnancy, labour, and 
neonatal history with attention to the presence or absence of specific complications; (2) a general paediatric examination; (3) specific investigations to exclude: gastro-oesophageal reflux (24-hour oeosphageal $\mathrm{pH}$ studies, barium swallow, radionuclide milk scan, chest radiograph); abnormal breathing pauses and patterns in sleep (polygraphic studies of breathing and sleep-state); upper airways disease (lateral airways radiographs and bronchoscopy); seizures, especially temporal lobe fits (12 lead electroencephalogram); thiamine deficiency (venous blood sample for red blood cell, transketolase enzyme activity).

The tests varied according to the clinical features and the time at which the infant was studied - that is in the second year we introduced radionuclide milk scans and lateral airways radiographs.

\section{Specific investigations.}

\section{Studies of gastro-oesophageal reflux and aspiration}

An oesophageal pH electrode (Beckman). This was passed via the nostril into the stomach to ensure an acid $\mathrm{pH}$, then withdrawn to $3-5 \mathrm{~cm}$ above the gastrooesophageal junction. This position was checked radiologically in all infants and the probe securely taped at the nose. The electrode, attached to a $\mathrm{pH}$ analyser (Orion), was calibrated before use in standard buffer solutions.

Reflux was scored according to the criteria used by Jolley et al. ${ }^{9}$ and Herbst et al..$^{10}$ in their assessment of normal children. This was based on the frequency and duration of reflux in the upright and supine positions during wakefulness and sleep during a 24-hour period. They found the score that best discriminated normal infants from infants with reflux was based on the $>2$ hour post-feeding period. This was calculated for infants in this study and scores of 40-70 were classified as mild reflux, $70-100$ as moderate, and $>100$ as severe reflux.

Barium swallow. This was performed using a standard technique in the one department of paediatric radiology. While the infant drank barium from a bottle, the upper pharynx and oesophagus were examined radiologically for evidence of defective swallowing mechanisms, tracheal aspiration, and anatomical abnormalities. Testing for gastrooesophageal reflux included positioning the infant so that barium outlined the fundus of the stomach and gastro-oesophageal junction; abdominal compression was not used. The gastric outlet was also examined for evidence of obstruction.

Reflux was classified as severe if significant amounts of barium reached the pharynx; moderate if barium extended to the middle or upper third of the oesophagus; mild if barium entered only the lower oesophagus.

Radionuclide 'milk scan'. Technetium-99m-labelled sulphur colloid was mixed with the infant's usual milk formula. After this feeding, a second feed of non-labelled milk was given to clear radioactive material from the mouth and pharynx. The infant then was scanned in the supine, prone, right and left lateral positions for the first hour for evidence of reflux. Two hours after the first ingestion of milk, images of the lung were taken to examine for aspiration. A second dose of labelled milk was given at $\mathbf{2 4 0 0}$ hours and lung images again examined 12 hours later for any further evidence of aspiration.

Severity of the reflux was classified according to the level reached by radioactive milk in the oesophagus and pharynx and was the same as for the barium swallow.

Chest radiograph. This was performed as a general screening procedure and to examine for lesions suggestive of aspiration.

\section{Polygraphic studies of breathing, reflux, and sleep}

Multichannel pen recordings were made in a quiet room for long periods, generally from 1200 to 1800 hours and then from 2200 to 0600 hours. Sleep state was defined by electroencephalogram (EEG), electro-oculogram, submental electromyogram, breathing pattern, and behavioural observations. Breathing was assessed by recording abdominal diaphragmatic movement from an abdominal strain gauge and airflow from a nasal thermistor. The electrocardiogram and beat-by-beat heart rate were also recorded. Oesophageal pH was recorded with these traces; in addition an output to a slow penrecorder enabled a continuous 24-hour pH assessment to be made. Ambient temperature and cutaneous or rectal temperature were monitored throughout the recording to confirm normothermia.

\section{Studies of upper airways disease}

The two methods used were: lateral airway radiographs and bronchoscopy under general anaesthesia. The endoscopic examination was performed by one surgeon and included: examination of the larynx, in particular vocal cord movement; the trachea, for evidence of compression or stenosis; and the oesophagus for reflux oesophagitis.

\section{Electroencephalography}

A conventional 12-lead EEG during wakefulness and sleep was used to detect seizure activity.

\section{Thiamine status}

This was evaluated by erythrocyte transketolase (ETK) activity of venous blood, before and after the 
addition of thiamine pyrophosphate (TPP). This was measured according to a modification of the method of Schouten et al. ${ }^{11}$ The indices used to define deficiency were a reduction in ETK activity below 140 units, or a rise in ETK activity on addition of thiamine pyrophosphate (the TPP effect) $>20 \%$; TPP effect in the range $15-20 \%$ was defined as marginal deficiency. These definitions are in agreement with other reports and were based on previous surveys of Australian adults and children. ${ }^{2}$

\section{Results}

Age distribution. The age distribution at which the first near-miss incident occurred is illustrated in Fig. 1 (upper panel). This compares the age of the first 39 near-miss infants studied with the age at death of 70 SIDS infants for the same 12-month period (lower panel). The distribution is similar but the peak age for near-miss episodes is shifted to the left.

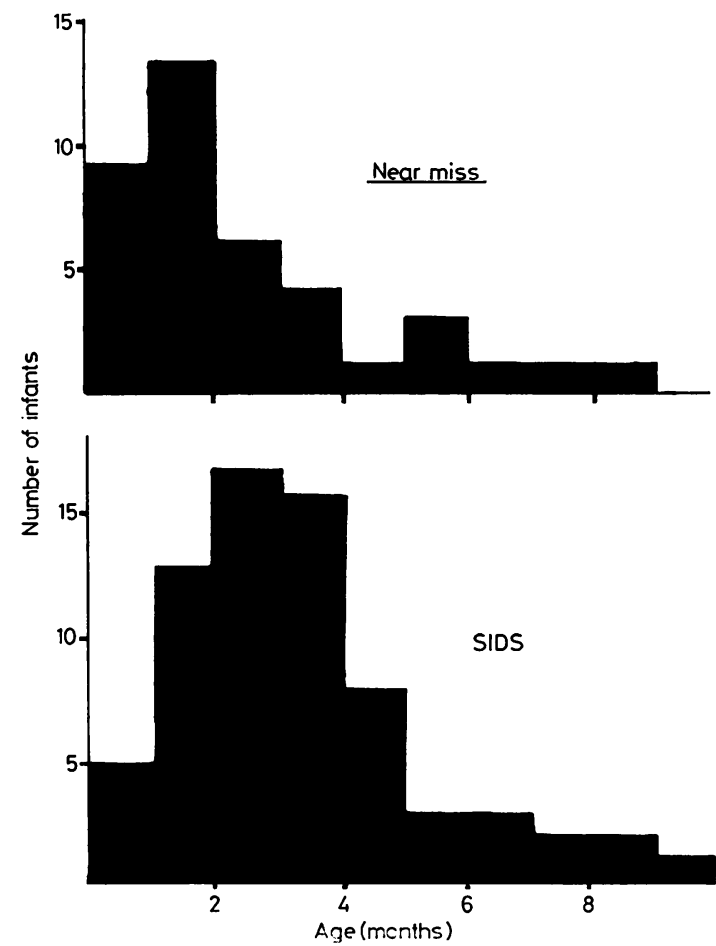

Fig. 1 Age distribution of the first near-miss episode, in the 39 near-miss SIDS infants investigated during the first year of the study (upper panel). Age at death of the 76 infants who died from SIDS during the same 12-month period (lower panel).
Precipitating factors. Usually the near-miss episode occurred during presumed sleep but occasionally similar episodes were observed during wakefulness, especially during or after crying. In 32 infants, there was a history of more than one episode. Frequently a minor illness preceded the incident: an upper respiratory tract infection, generally reported as sniffles and a blocked nose, preceded the near-miss episode in $45 \%$ of infants; occasionally there was a report of vomiting and poor feeding.

General clinical history and examination. A feature of these infants' history was the high proportion of infants with at least one complication during the pregnancy, labour, or neonatal period (Table). No one complication was especially common.

The mean birthweight was 2.9 (range $0 \cdot 8-3.8$ ) $\mathrm{kg} ; 12$ near-miss infants and 3 twins were of low birthweight $(<2.5 \mathrm{~kg})$. The mean gestational age was 38 (range 27-40) weeks; 14 near-miss infants and 3 twins were preterm ( $<37$ weeks' gestation). Five infants were small-for-dates ( $<10$ centile), 2 of whom were twins.

The clinical examination of these infants after the near-miss incident was generally normal. There was often a time-delay (mean 24 days) between the first near-miss event and hospital admission.

In only 2 infants were there clear abnormalities on examination: these included abnormal neurological signs in the surviving triplet of a SIDS infant, detected early in a complicated neonatal course; and 1 near-miss infant who had a rash typical of seborrhoeic dermatitis.

Studies to detect gastro-oesophageal reflux and evidence of aspiration

Oesophageal $p H$ studies. Fifty infants were studied by this method. The results are summarised in Fig. 2

Table Frequency of pregnancy, labour, and neonatal complications in 58 near-miss SIDS infants, according to maternal history

\begin{tabular}{|c|c|c|c|c|c|c|}
\hline \multirow{2}{*}{$\begin{array}{l}\begin{array}{l}\text { No of } \\
\text { complications }\end{array} \\
0 \\
1\end{array}$} & \multicolumn{2}{|c|}{ Pregnancy* } & \multicolumn{2}{|c|}{$\begin{array}{l}\text { Labour and } \\
\text { delivery } \dagger\end{array}$} & \multicolumn{2}{|c|}{ Neonatal } \\
\hline & $\left.\begin{array}{r}34 \\
17 \\
6 \\
1\end{array}\right\}$ & $\begin{array}{l}88 \% \\
12 \%\end{array}$ & $\left.\begin{array}{r}23 \\
19 \\
13 \\
3\end{array}\right\}$ & $28 \%$ & $\left.\begin{array}{r}26 \\
17 \\
9 \\
6\end{array}\right\}$ & $\begin{array}{l}74 \% \\
26 \%\end{array}$ \\
\hline
\end{tabular}

Complications listed on questionnaire

*Threatened spontaneous abortion, infection and fever, multiple pregnancies, hydramnios, pre-eclamptic toxaemia.

†Preterm labour, caesarean section, forceps, induction of labour, breech delivery, fetal distress, precipitate delivery.

$\ddagger$ Respiratory distress syndrome, apnoea in first 24 hours, feeding problems, jaundice, infection. 
$\mathrm{pH}$

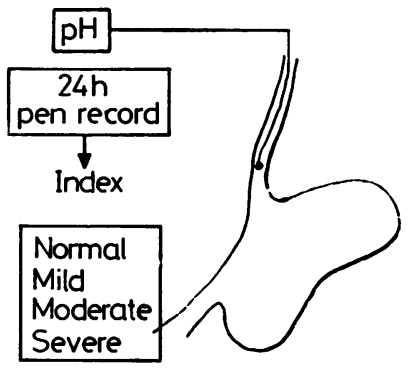

50

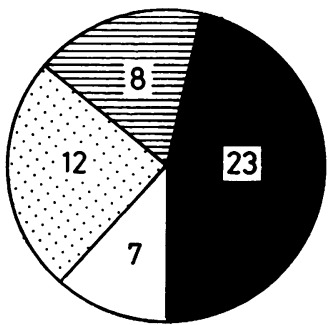

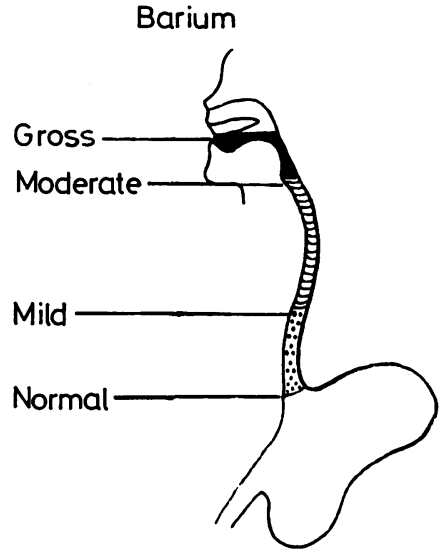

Isotope 'milk scan'

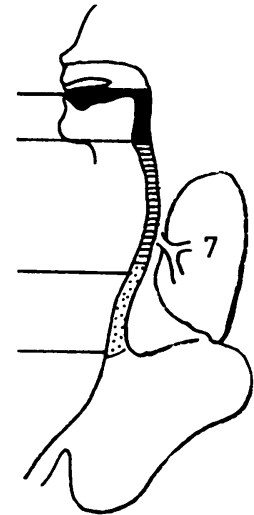

59

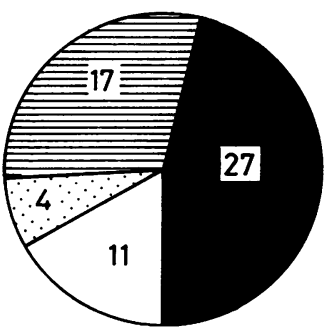

Fig. 2 High incidence and frequent severity of gastro-eosophageal reflux in high-risk SIDS infants, as studied by 24-hour pen recordings of oesophageal $\mathrm{pH}$, barium swallow', and radionuclide 'milk scan'. Index of severity for the barium and 'milk scan' investigations (upper panel) is indicated by' the height of the reflux column; in addition, 7 infants showed evidence of aspiration on the 'milk scan'. Assessment of severity' of reflux by' oesophageal pH probe is given under methods. Number of infants with severe $\square$, moderate 县, mild 3 , and no reftux $\square$ is indicated by the shaded areas in the pie charts.

(left panel). This depicts the large number of infants with significant reflux. Nearly half were classified as severe with a score exceeding 100.

In the first 20 infants, the relationship between reflux and sleep-state was evaluated. This demonstrated a high incidence of reflux in sleep (13 out of 20 infants). Reflux was linked to sleep-state: it occurred in active and indeterminate sleep, but never in quiet sleep. ${ }^{13}$

Barium swallow. Of the 59 infants studied, 48 had evidence of reflux. More than half of these showed gross reflux with barium refluxing to the level of the upper pharynx and nose (Fig. 2, middle panel).

The 45 infants in whom both $\mathrm{pH}$ and barium studies were performed indicated that severe reflux on pH studies was more frequently associated with gross reflux on barium study (15 out of 22 infants).
There was no clear correlation between lesser degrees of reflux.

Milk scan. This investigation was introduced in the second year of the study. There were 21 out of 27 abnormal results and most (14 infants) of these were classified as gross (Fig. 2, right panel). Seven infants also had evidence of pulmonary aspiration: 5 of those with gross reflux, 1 with moderate, and 1 with mild reflux.

There were 23 infants examined both by $\mathrm{pH}$ studies and milk scans. A correlation was found only in infants with severe reflux on $\mathrm{pH}$ assessment. In these 11 infants, 8 also had gross reflux on milk scan.

Chest radiograph. This was reported as normal in 58 infants and abnormal in 6 infants. In 4 infants 
the lesions consisted of small opacities or increased markings in the right or left base consistent with inflammation or aspiration. In these 4 infants, reflux was demonstrable.

In 3 of these 4 infants, conservative management failed and fundoplication of the oesophagus was performed.

Polygraphic studies of breathing, reflux, and sleep-state

All infants were studied for many hours during many sleep cycles; in most this comprised an overnight study of at least 10 (range 6-48) hours. This showed a clear abnormality in breathing during sleep in 13 infants.

Seven infants displayed prolonged apnoea of $>15$ seconds in sleep; pulmonary resuscitation during the recording was required in 2 infants. In 3 infants, the percentage of sleep-time spent in periodic breathing as defined by Kelly and Shannon, ${ }^{7}$ exceeded control values. In 1 infant a sudden, unexplained decrement in breathing rate occurred with only 5 breaths in 60 seconds; normal breathing resumed spontaneously. In 2 infants, sudden r regularities of breathing pattern developed, some- times with apnoea in association with abnormal EEG patterns, and clinical features consistent with a seizure (Fig. 3). In one, temporal-lobe epilepsy was confirmed by a 12 lead EEG; in the other infant, the formal EEG was normal but several months later the infant had 2 episodes of tonic-clonic seizures associated with loss of consciousness.

The relationship between breathing, reflux, and sleep-state was also evaluated from these studies. This has been reported previously. The major finding was that there was no statistical difference ( $\chi^{2}$ analysis) in the number of pauses in breathing of greater than 10 seconds which occurred during reflux (oesophageal $\mathrm{pH}<4$ ) compared with periods without reflux $(\mathrm{pH}>4)$. Nor was there a difference in the mean breathing rate in the 20 seconds before compared with immediately after reflux, for each sleep-state in which reflux occurred.

Studies for evidence of upper airways obstruction, laryngeal, and tracheal disease

Lateral airway radiographs. In the 21 infants examined, 2 were reported as abnormal with

\section{EEG $1 \mathrm{mV}$ c.}

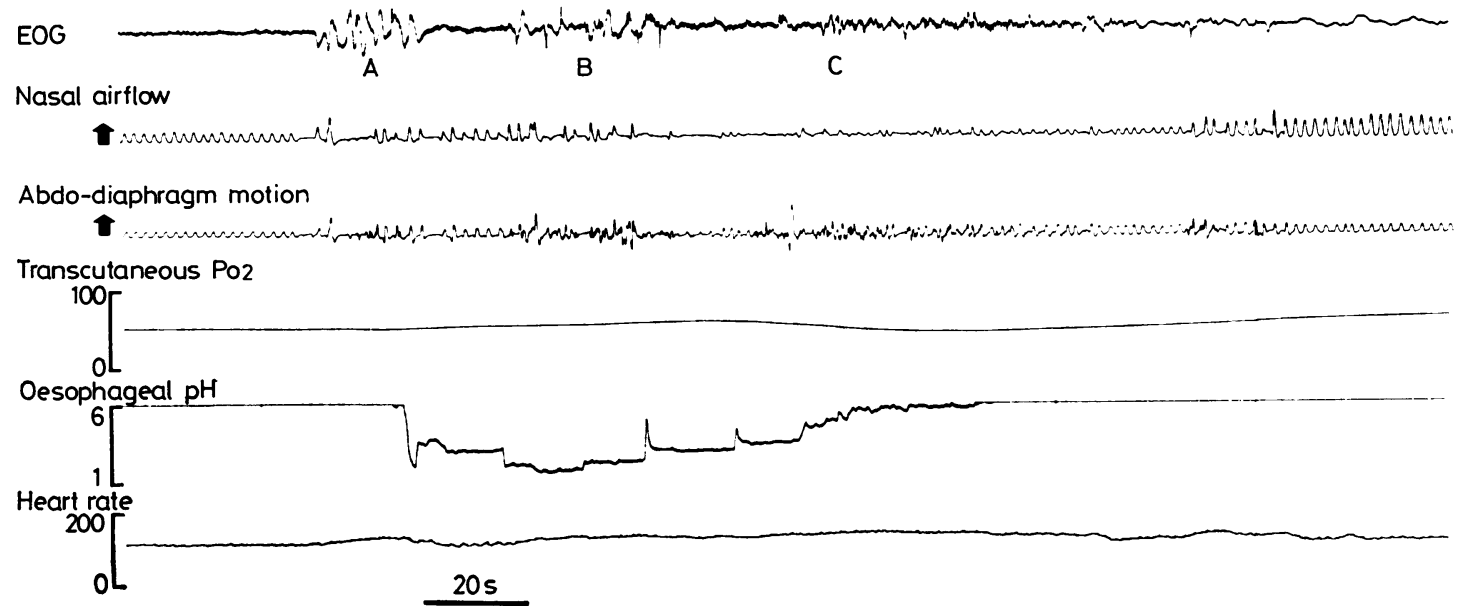

Fig. 3 Polygraphic traces and behavioural observations indicating seizure activity in a 16-week-old infant who presented with several near-miss episodes. Abnormal high voltage, spiking EEG was followed by interruption to the regular breathing pattern and a pronounced fall in the transcutaneous $P_{o_{2}}$ values from 70 to $45 \mathrm{mmHg}$. During this period a sudden decrease in the oesophageal pH from 6 to 1.5 heralded gastro-oesophageal reflux. These abnormal pen recordings were associated at $A$ with slow repetitive movements of the head to the left, at $B$ movement of the left arm and left leg, and at $C$ with salivation, tongue thrusting, and cyanosis. A regular breathing pattern, and normal transcutaneous $P_{2}$ values coincided with the resumption of a normal EEG trace. EEG = electroencephalogram, EOG = electro-oculogram; Abdo diaphragm motion $=$ abdominal diaphragm motion. 
narrowing of the trachea in the chest. Bronchoscopy confirmed innominate artery compression of the trachea in 1 infant; no abnormality was found in the other.

Bronchoscopy. This was performed in 15 infants. The usual indications were either clinical or polygraphic evidence suggesting an obstructed upper airway. Abnormalities were found in 5 infants.

In 2 infants, innominate artery compression of the trachea accounted for $50 \%$ and $70 \%$ occlusion of the lower trachea.

Tracheomalacia was demonstrable in 2 infants. They presented with the sudden onset of severe cyanotic episodes 6 weeks after the successful and uncomplicated primary repair of a tracheooesophageal fistula.

A further infant displayed a small left vocal nodule; the significance of this remains unclear.

Detection of seizure activity by the electro-
encephalogram

In 59 infants in whom this test was conducted, 4 showed abnormal features: 2 had temporal lobe foci of seizure activity, and 2 had generalised epileptogenic activity.

Before the EEG diagnosis, clinical evidence of fits had not been recognised. Careful observation later confirmed minor 'absences' with turning of the head to the right, excessive salivation, and associated apnoea in 2 of the 4 infants. Two further infants later displayed repeated tonic-clonic convulsions; their previously normal EEGs were unchanged.

All 6 of these infants also had moderate to severe gastro-oesophageal reflux as assessed by $\mathrm{pH}$ recording and barium swallow. Neither fits nor reflux therefore represents a mutually exclusive diagnosis in near-miss infants. However, the polygraphic recordings in 1 infant (Fig. 3) suggest that reflux may be an integral part of the autonomic dysfunction accompanying temporal lobe seizures.

Assessment of thiamine status by red blood cell, transketolase enzyme activity

Venous blood was successfully collected from 43 infants. In 10 out of 38 unselected near-miss SIDS infants and 2 out of 5 surviving twins of a SIDS infant, the values were compatible with thiamine deficiency; the ETK activity was less than 140 in 11 infants, with 2 of these having a TPP effect greater than $20 \%$; an additional infant had a TPP effect of $22 \%$ (ETK activity 156 units).

The one outstanding factor found to be common among the deficient infants was a family history of SIDS: 5 of the 12 infants had a family history of SIDS; these occurred in 8 first-degree family members. An additional infant's sibling had also had a near-miss episode. By contrast, only 5 out of the 31 non-thiamine deficient high-risk infants had a family history of SIDS; these occurred in 5 family members. This difference is statistically significant $\left(5 / 12\right.$ versus $\left.5 / 31, \chi^{2}, P<0.05\right)$.

Other investigations. Screening tests to exclude occult infection and metabolic disturbances included: haemoglobin and differential white cell count, microscopy and culture of urine, blood urea and serum electrolytes, calcium and magnesium, and a fasting blood glucose level. These were all normal.

\section{Discussion}

Our results include a study of 64 infants referred to the high-risk for SIDS clinic during a 2-year period. Although there are reports on near-miss SIDS infants, such reports generally concentrate on specific abnormalities in breathing and there is no overview summarising the clinical findings.

We found that an unselected group of infants, who were classified as 'near-miss' - that is, found blue and not breathing but who rapidly revived-had a variety of problems. These included sleep apnoea, gastro-oesophageal reflux, seizures, innominate artery compression of the trachea, tracheomalacia, and thiamine deficiency. Only 13 out of 64 infants had breathing abnormalities.

The respiratory abnormalities that were found were sleep related: they included prolonged central apnoea and excessive periodic breathing. One infant breathed very slowly with disturbed breathing patterns, and apnoea associated with seizures. Some of these infants required resuscitation during polygraphic recording. In 2 infants, apnoea was very likely precipitated by drugs (diazepam and phenobarbitone). It is possible that many more of them had apnoea intermittently - as for example during an upper respiratory tract infection; the delay in our sampling may have missed such apnoeas.

Claims that prolonged apnoea occurred while infants were at home on respiratory monitors have been based on parental diaries of monitor alarms. ${ }^{13}$ The difficulties of assessing apnoea in this way without tape-recordings have been stressed. ${ }^{14}$ This additional methodology is necessary in order to separate breathing defects from technical artefacts. At the present time, intensive technological efforts are being made to exclude artefacts and provide data on the true incidence of apnoea at home.

The extensive experience of the Boston Children's 
Hospital showed a high incidence of periodic breathing in near-miss infants. ${ }^{7}$ We did encounter periodic breathing in infants, but it was not a prominent feature of the whole group. Differences of this type may be due to the selection of infants referred to units in different parts of the world-the presence of some identified abnormality removing the classification of 'near-miss SIDS'.

Perhaps the most important and surprising finding was the high incidence of gastro-oesophageal reflux (Fig. 2). Several authors have drawn attention to the occurrence of near-miss episodes in infants with proved gastro-oesophageal reflux..$^{15}{ }^{16}$ Some of these infants have subsequently died, and at necropsy the findings have been identical with those in other cases of SIDS.

Reflux of milk or gastric contents can produce asphyxia by several mechanisms. Firstly, obstruction can occur from foreign material; this partial obstruction can become complete if the pharyngeal airway collapses when sub-atmospheric pressure is generated by augmented inspiratory efforts. ${ }^{17}$ Secondly, apnoea can be induced by a laryngeal chemoreceptor reflex. ${ }^{18}$ Thirdly, pulmonary gasexchange can be deranged by intrapulmonary veno-arterial shunts and regional mismatching of ventilation/blood flow; the defects can develop rapidly, and be severe regardless of $\mathrm{pH}^{19}$ Fourthly, milk antigens can provoke broncho-constriction from anaphylaxis if there has been previous sensitisation. ${ }^{20}$

Many clinicians point out that reflux is so common in babies that it might well be regarded as normal and therefore an unlikely cause of asphyxia. We did not obtain data in healthy infants for ethical reasons and there is little information available.

Our most important observation was the link between reflux and active sleep. The reason for the importance is that other work has shown that in this sleep-state cough is suppressed and laryngeal stimuli are likely to provoke severe apnoea, ${ }^{21}$ the reflex augmentation of intercostal muscle activity during obstructed breathing is lost $;{ }^{22}$ pulmonary $\mathrm{O}_{2}$-stores are reduced, so hypoxaemia develops rapidly $;{ }^{23}$ and the reflex defence to resultant hypoxaemia, both ventilatory and arousal responses, are particularly depressed. ${ }^{24}$

However, the fact that reflux may be so common suggests that this in itself may not be sufficient to cause death; rather an additional defect-for example, a defective arousal response to such stimuli as laryngeal-induced apnoea or airways obstruction -must also be involved. Sleep fragmentation can result in depressed arousal responses to larygneal stimuli, as well as to the asphyxial stimuli of lowered $\mathrm{O}_{2}$ and increased $\mathrm{CO}_{2}$ tensions. ${ }^{25}$ Such a mechanism is likely in infants with nasal congestion associated with the common cold. Such infections were often associated with the clinical histories of the near-miss episodes in this study and are well documented as a common prelude to the SIDS.

In our experience reflux was not linked to apnoea, and other studies have confirmed this. ${ }^{26}$ Presumably many episodes of reflux will occur for any given aspiration into larynx or lungs, and therefore any expectation of apnoea. This shows the need for a methodology for studying reflux which documents the incidence of reflux to different levels over long periods of time in sleep. We need to know the physiological factors which normally protect the airways when 'high reflux' occurs.

This study indicated that another important sleeprelated cause of asphyxia is seizures. As is well known, temporal lobe seizures are difficult to diagnose with present methodology. This diagnosis was made in 2 infants.

Several observations suggest that temporal lobe seizures may cause sudden unexpected death. Firstly, adults with this diagnosis subsequently have had 'near-misses', or have died suddenly in sleep. ${ }^{27}$ Secondly, animal studies indicate that seizure provocation in part of the temporal lobe, the amygdala, is associated with failure of the usual reflex respiratory responses to obstructed breathing. ${ }^{28}$ This observation suggests that a diagnosis of reflux in an infant, who also has such seizures (Fig. 3), may be particularly dangerous. Thirdly, 2 of our near-miss infants each had one sibling die from SIDS, and another sibling exhibit fits; one of these siblings with seizures also subsequently died, probably during a seizure, since no other cause was found at necropsy.

Unfortunately in infants with suspected, but unproved, seizures, treatment with anti-convulsants cannot be used without risk, since there is a danger of unmasking respiratory problems if the diagnosis is incorrect.

In a number of our children, congenital abnormalities disturbing the upper airways were detected often only after extreme diagnostic difficulty-for example in 1 infant bronchoscopy on one occasion did not show tracheomalacia, and it was only on the second bronchoscopy that an abnormality was detected. Possibly dynamic compression of airways is manifest only when ventilation is fortuitously stimulated. This shows the need for improved diagnostic methodologies in this area, possibly using $\mathrm{CO}_{2}$-rebreathing stimuli. Our experience with 2 infants in this study suggests that bronchoscopy is indicated in infants who develop signs of upper airways obstruction when crying forcibly.

The possible relevance of thiamine deficiency to 
SIDS has been reviewed by one of us. ${ }^{29}$ Infantile thiamine deficiency can produce deaths which are sudden and unexpected, and typically occur between ages 2 and 4 months. ${ }^{30}$ The significant number of deficient infants in our high-risk SIDS group and the high familial SIDS incidence, suggests that such infants are potentially at risk of sudden death. This deserves clinical attention and appropriate treatment, regardless of the more complex and unresolved problem of evaluating SIDS in general.

Our experience suggests that the infants being referred to our near-miss SIDS clinic are relevant to the SIDS problem. Firstly, it has been found that the age incidence of SIDS deaths and near-miss incidents is similar in distribution but for a shift to the left in peak incidence in the near-miss infants (Fig. 1). The typical age distribution of SIDS deaths between 2 and 4 months, with few deaths after 6 months, is unusual, and is an important research clue. The only known causes of death in infancy with an identical distribution are infantile thiamine deficiency ${ }^{30}$ and infantile botulism. The slightly earlier age for near-miss episodes suggests that at least some SIDS infants are symptomatic but unrecognised before death.

Secondly, we have unfortunately had 2 SIDS deaths in our near-miss group despite all therapeutic efforts. The concept of near-miss SIDS has also been supported by experience in other clinics where such infants have gone on to a disproportionate incidence of SIDS deaths in relation to the population, despite intervention. ${ }^{13}$

In summary, our findings indicate that both SIDS and near-miss may consist of a syndrome with a number of different underlying disorders. This study stresses that many other mechanisms for asphyxia exist, in addition to idiopathic apnoea, in infants presenting in this way.

Investigation of these infants was made possible by many colleagues, especially $\mathrm{Dr}$ I Reid, Dr J McDonald, Dr $\mathbf{R}$ Howman-Giles, Dr J Nairn, Dr V McCauley, and Dr D Callanan, and the referring physicians from the Royal Alexandra Hospital for Children and Prince of Wales Children's Hospital, Sydney. We thank Sister A Cubis and Sister R Hales for assistance with polygraphic recordings.

This research was supported by the National Health and Medical Research Council and the Apex Sudden Infant Death Research Foundation of Australia.

\section{References}

1 Steinschneider A. Prolonged apnea and the sudden infant death syndrome: clinical and laboratory observations. Pediatrics 1972; 50: 646-54.
2 Shannon D C, Kelly D H, O'Connell K. Abnormal regulation of ventilation in infants at risk for suddeninfant-death syndrome. $N$ Engl J Med 1977; 297: 747-50.

3 Kelly D H, Shannon D C, O'Connell K. Care of infants with near-miss sudden infant death syndrome. Pediatrics $1978 ; 61: 511-4$.

4 Guilleminault T C, Ariagno R L, Forno L S, Nagel L, Baldwin R, Owen M. Obstructive sleep apnea and nearmiss for SIDS. I. Report of an infant with sudden death. Pediatrics 1979; 63: 837-43.

5 Peterson D R, Chinn N M, Fisher L D. The sudden infant death syndrome: repetitions in families. $J$ Pediatr 1980; 97: 265-7.

6 Brady J P, Ariagno R L, Watts J L, Goldman S L, Dumpit F M. Apnea, hypoxemia, and aborted sudden infant death syndrome. Pediatrics $1978 ; 62: 686-91$.

7 Kelly D H, Shannon D C. Periodic breathing in infants with near-miss sudden infant death syndrome. Pediatrics 1979; 63: 355-60.

8 Hunt C E, McCulloch K, Brouillette R T. Diminished hypoxic ventilatory responses in near-miss sudden infant death syndrome. J Appl Physiol 1981 ; 50: 1313-7.

9 Jolley S G, Johnson D G, Herbst J J, Pena A R, Garnier R C. An assessment of gastro-oesophageal reflux in children by extended $\mathrm{pH}$ monitoring of the distal esophagus. Surgery 1978; 84: 16-24.

10 Herbst J J, Minton S D, Book L S. Gastro-esophageal reflux causing respiratory distress and apnea in newborn infants. J Pediatr 1979; 95: 763-8.

11 Schouten H, Statius Van Eps L W, Struyker Boudier A M. Transketolase in blood. Clin Chim Acta 1964; 10: 474-6.

12 National Health and Medical Research Council of Australia. Summary of a report on the thiamine status of Australian people. Med J Aust 1978; i: 232-5.

13 Jeffery H E, Reid I, Rahilly P, Read D J C. Gastroesophageal reflux in 'near-miss' sudden infant death infants in active but not quiet sleep. Sleep 1980; 3: 393-9.

14 Jeffery H E, Cunningham R A, Cubis A, Read D J C. New methods to separate artifacts from normal and defective breathing patterns in different sleep-states if infants are monitored at home. Aust NZ J Med 1981; 11: 406-11.

15 Leape L L, Holder T M, Franklin J D, Armoury R A, Ashcraft K W. Respiratory arrest in infants secondary to gastroesophageal reflux. Pediatrics $1977 ; 60$ : 924-8.

16 Herbst J J, Book L S, Bray P F. Gastro-esophageal reflux in the 'near-miss' sudden infant death syndrome. J Pediatr 1978; 92: 73-5.

17 Tonkin S L, Partridge J, Beach D, Whiteney S. The pharyngeal effect of partial nasal obstruction. Pediatrics $1979 ; 63: 261-71$.

18 Johnson P, Salisbury D M, Storey A T. Apnea induced by stimulation of sensory receptors in the larynx. In: Bosma J F, Showacre J, eds. Development of upper respiratory anatomy and function. Washington: US Government Printing Office, 1975: 160-83.

19 Schwartz D J, Wynne J W, Gibbs C P, Hood C I, Kuck E J. The pulmonary consequences of aspiration of gastric contents at $\mathrm{pH}$ values greater than 2.5. Am Rev Respir Dis $1980 ; 121$ : 119-26.

20 Devey M E, Anderson K J, Coombs R R A, Henschel M J, Coates M E. The modified anaphylaxis hypothesis for cot death. Anaphylactic sensitization in guinea-pigs fed cows' milk. Clin Exp Immunol 1976; 26: 542-8.

21 Sullivan C E, Murphy E, Kozar L F, Phillipson E A. Waking and ventilatory responses to laryngeal stimulation in sleeping dogs. $J$ Appl Physiol 1978; 45: 681-9.

22 Henderson-Smart D J, Read D J C. Depression of intercostal and abdominal muscle activity and vulnerability to asphyxia during active sleep in the newborn. 
In: Guilleminault C, Dement W C, eds. Sleep apnea syndromes. Proceedings of Kroc Foundation Symposium 1977. New York: Liss, 1978: 93-117.

${ }^{23}$ Henderson-Smart D J, Read D J C. Reduced lung volume during behavioral active sleep in the newborn. $J$ Appl Physiol 1979; 46: 1081-5.

24 Jeffery H E, Read D J C. Ventilatory responses of newborn calves to progressive hypoxia in quiet and active sleep. $J$ Appl Physiol 1980; 48: 892-5.

25 Bowes G, Phillipson E A. Arousal, ventilatory, and airway responses to laryngeal stimulation following sleep fragmentation (abstract). Am Rev Respir Dis 1980; 121: Supplement 316

26 Walsh J K, Farrell M K, Keenan W J, Lucas M, Kramer M. Gastroesophageal reflux in infants: relation to apnea. J Pediatr 1981; 99: 197-201.

27 Nelson D A, Ray C D. Respiratory arrest from seizure discharges in the limbic system. Arch Neurol 1968; 19: 199-207.

28 Reis D J, McHugh P R. Hypoxia as a cause of bradycardia during amygdala stimulation in the monkey. Am J Physiol 1968; 214: 601-10.

29 Read D J C. The aetiology of the sudden infant death syndrome: current ideas on breathing and sleep and possible links to deranged thiamine neurochemistry. Aust NZJ Med 1978; 8: 322-36.

30 Burgess R C. Beriberi: infantile beriberi. Fed Proc 1958; 17: Supplement 2, 39-48.

Correspondence to Dr Heather E Jeffery, Department of Physiology, University of Sydney, New South Wales 2006, Australia.

Received 19 August 1982

\section{British Paediatric Association}

$\begin{array}{ccc}\text { Annual meetings } & \\ 1983 & 12-16 \text { April } & \text { York University } \\ 1984 & 10-14 \text { April } & \text { York University } \\ 1985 & 16-20 \text { April } & \text { York University } \\ 1986 & 15-19 \text { April } & \text { York University } \\ 1987 & \text { 7-11 April } & \text { York University }\end{array}$

